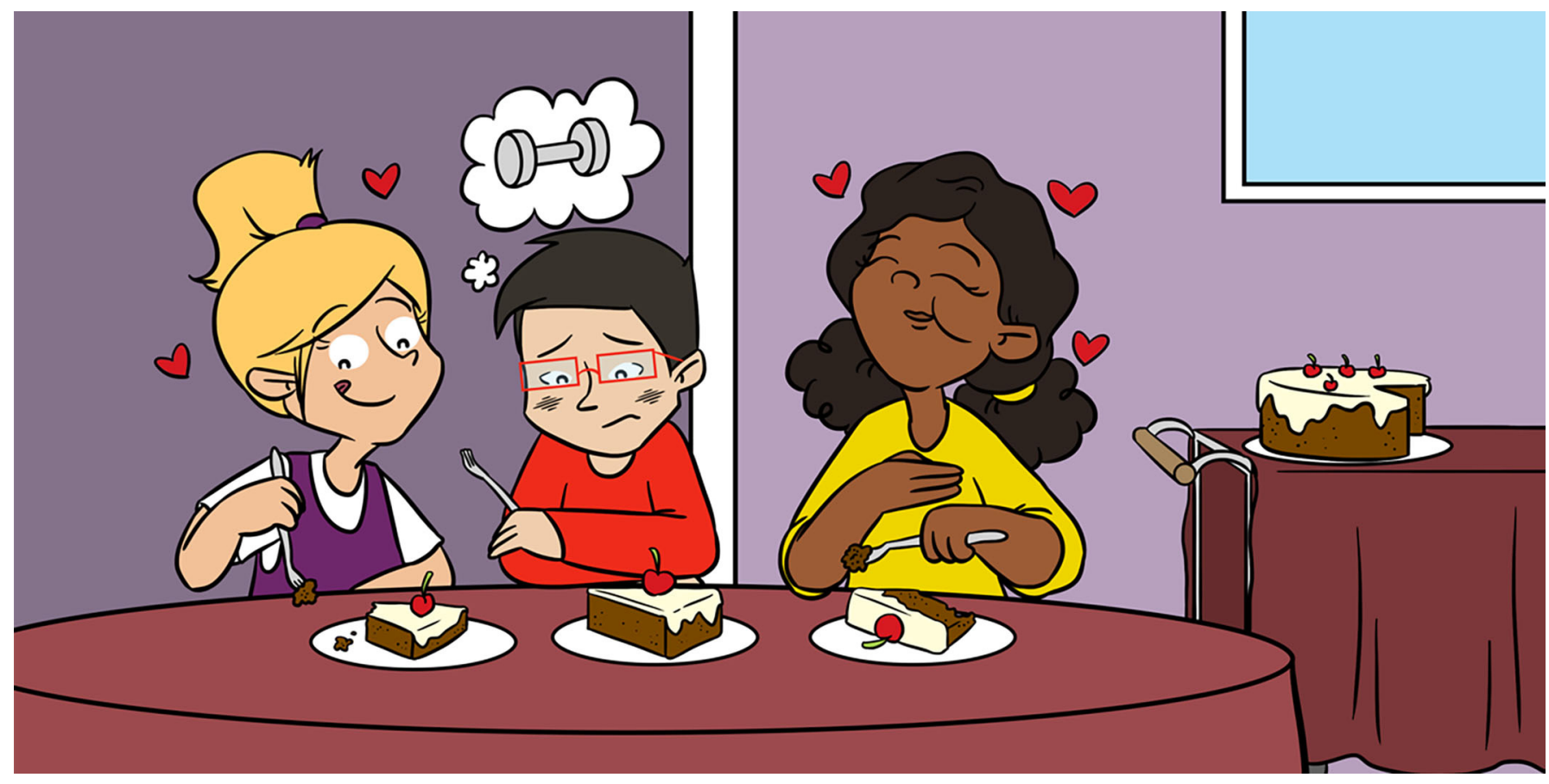

\title{
TAKING A BITE OUT OF EATING DISORDERS: FACTS AND MYTHS
}

\section{Kara A. Christensen ${ }^{1 *}$ and Kelsey E. Hagan ${ }^{2}$}

${ }^{1}$ Department of Psychology, University of Kansas, Lawrence, KS, United States

${ }^{2}$ Department of Psychiatry, Columbia University Irving Medical Center, New York, NY, United States

\section{YOUNG REVIEWERS:}

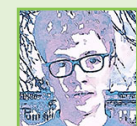

JOHANNES

AGE: 13

NIKITA

AGE: 12
Eating disorders are serious mental illnesses that are more common than many people realize. Because eating disorders have such negative physical, psychological, and social effects, identifying and treating eating disorders is very important. In this article, we present symptoms of four different eating disorders: anorexia nervosa, bulimia nervosa, binge eating disorder, and other specified feeding and eating disorder. Next, we provide information to help "bust" common myths about eating disorders. We then offer examples of early warning signs of eating disorders to look out for in others and yourself. Finally, we discuss how to seek help if you are concerned about your eating behaviors. Specifically, we describe types of treatments for youth with eating disorders. With increased knowledge about eating disorder facts, you can help to take a "bite" out of the stigma of eating disorders. 
Figure 1

Some common consequences of eating disorders. Common consequences of eating disorders can be social, psychological, and physical. These consequences are very serious and early intervention is important to keep people healthy. If you are experiencing problems related to eating behaviors, then it is best to discuss your concerns with a trusted person so that you can get the help you need from medical and psychological professionals.

\section{BODY MASS INDEX}

(BMI)

$\mathrm{BMI}$ is an estimate of one's body fat that is calculated using one's height and weight [BMI $=$ weight (in kilograms) divided by the square of the body height (in meters)]; larger BMIs are thought to indicate greater estimated body fat.

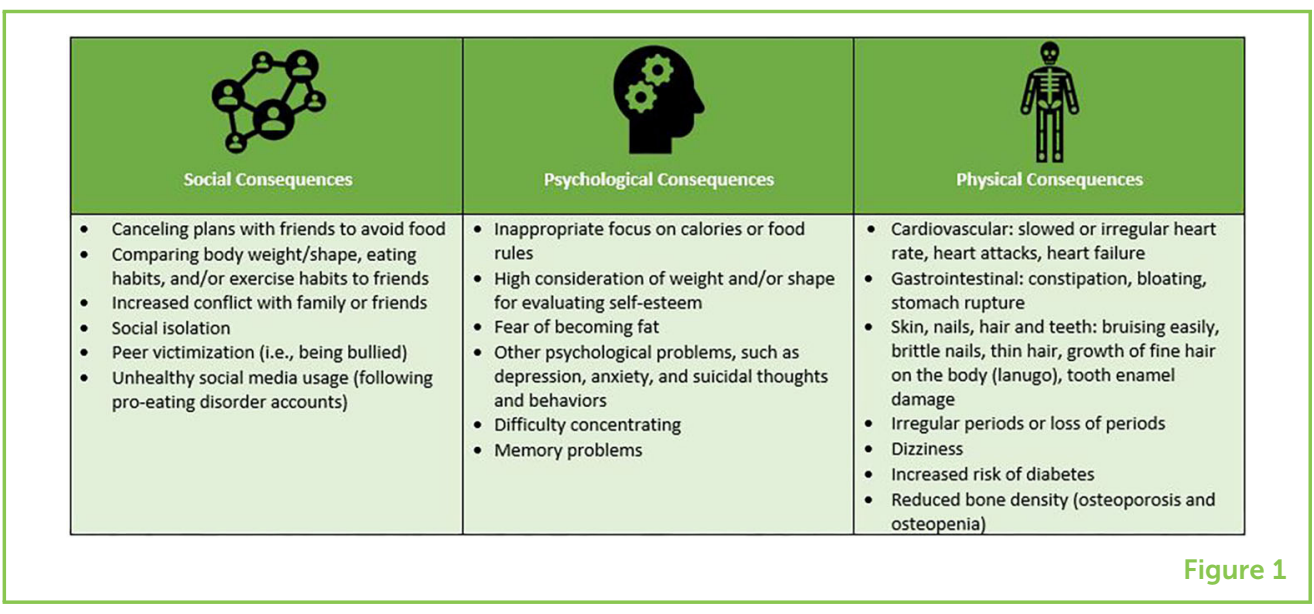

\section{INTRODUCTION}

Eating disorders are serious mental illnesses characterized by unhealthy eating behaviors and concerns about shape, weight, and/or maintaining control over eating. Eating disorders affect people of all ages, races, ethnicities, sexual orientations, gender identities, income levels, and countries of origin. Eating disorders are common; for instance, recent research found that one in five college students has an eating disorder [1]. This rate is similar to rates of anxiety and depression, which many people incorrectly think are more common than eating disorders.

People with eating disorders experience many physical, social, and psychological problems (Figure 1). Physically, people with eating disorders are at a higher risk for medical conditions, including heart problems (such as heart attacks), metabolic disorders (such as diabetes), and reduced bone density (including osteoporosis). Some people with eating disorders will have a very low body mass index (BMI). BMI estimates one's body fat, taking into account one's height (in kilograms) and weight (in meters); larger BMI numbers indicate greater estimated body fat. Socially, the shame and guilt that come with eating disorders may result in isolation. Psychologically, people with eating disorders commonly experience levels of anxiety and depression that make it difficult for them to function normally. Eating disorders have the highest mortality rate of any mental illness, due to medical complications caused by the eating disorder and/or death by suicide. Thus, preventing the development of eating disorders and providing effective treatment is very important.

\section{EATING DISORDER DIAGNOSES}

The Diagnostic and Statistical Manual, Fifth Edition (DSM-5) [2]-a guidebook for diagnosing mental illness-outlines four main eating disorder diagnoses (Figure 2): 
Figure 2

Eating Disorder

Diagnoses. The

Diagnostic and

Statistical Manual, Fifth

Edition (DSM-5), lists

the symptoms of eating

disorders, to help

doctors and other

healthcare providers to

diagnose

these illnesses.

\section{LAXATIVES AND \\ DIURETICS}

Any substance that may be used to increase the frequency of defecation (laxatives) or urination (diuretics).

\section{BINGE EATING}

Eating large amounts of food (much larger than typical), in a short period of time (i.e., $<2$ h) while feeling like one cannot stop eating or control what or how much they are eating.

\section{COMPENSATORY}

\section{BEHAVIOR}

Any behavior used to counteract the effects of eating or to influence body weight or shape, such as making oneself vomit, using laxatives and/or diuretics to lose weight, excessive exercise (i.e., $>2$ h), severely restricting food intake, and fasting for non-religious purposes (going more than $8 \mathrm{~h}$ without eating or skipping meals).

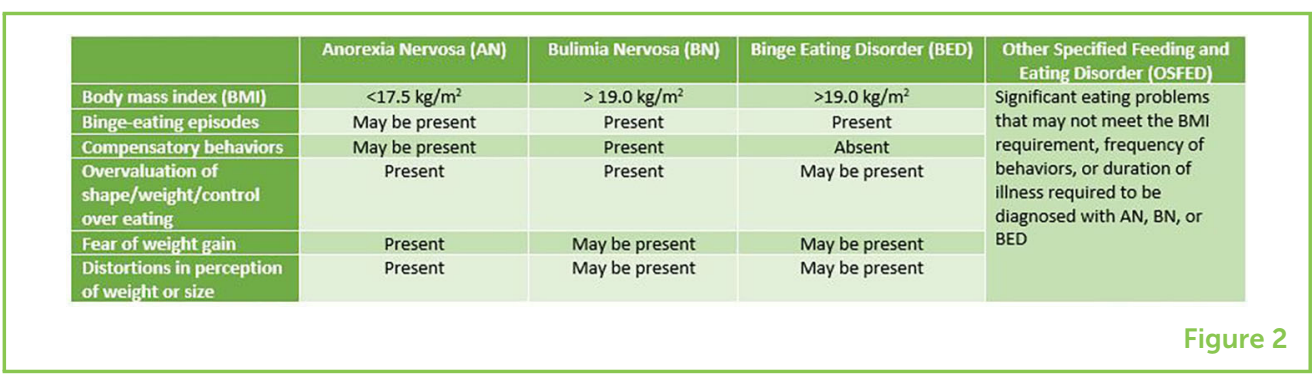

(1) Anorexia nervosa (AN) is characterized by extreme restriction of food intake that results in a significantly low body weight $(\mathrm{BMI}<17.5$ $\mathrm{kg} / \mathrm{m}^{2}$ ). Behaviorally, extreme dieting is the main symptom of $A N$, but people with AN may also use the following methods to control weight: excessive exercise, taking laxatives and/or diuretics (substances that cause increased defecation or urination), using diet pills or teas, and/or making themselves vomit. People with AN experience distressing thoughts, such as intense fears of weight gain and feeling fat even when underweight. People with AN may view being at a certain weight or wearing a certain clothing size as the biggest contributors to their self-worth, above other, more common factors, such as friendships, academic performance, and hobbies. A challenge with AN is that many people with the illness may not understand the seriousness of their symptoms. For instance, they may deny the negative effects that their eating behaviors and low weight have on their health.

(2) Bulimia nervosa (BN) is defined by the following three symptoms in persons with at least a healthy body weight $\left(\mathrm{BMI}>19.0 \mathrm{~kg} / \mathrm{m}^{2}\right)$ : (1) binge eating at least once a week for 3 months; (2) using compensatory behaviors at least once per week for 3 months; and (3) body image concerns. Binge eating occurs when a person eats a very large amount of food in a short amount of time and feels like they are out-of-control over their eating. A "very large" amount of food is commonly defined by the "pint plus" rule. That is, when a person eats a pint of ice cream plus another food item or other, similar amounts of food. People with BN use compensatory behaviors to counteract the effects of a binge episode and/or to control body shape and/or weight. Compensatory behaviors may include (but are not limited to) exercising excessively, restricting caloric intake, fasting (such as not eating for 8 or more hours), making oneself vomit, and taking laxatives and/or diuretics for weight control. BN can result in serious medical consequences, such as stomach rupture and tooth enamel decay.

(3) Binge eating disorder (BED) is defined as binge eating at least once per week for 3 months without using compensatory behaviors, in people with at least a healthy BMI. To be diagnosed with BED, binge eating episodes must be accompanied by at least three of the following symptoms: eating more rapidly than normal; eating until feeling uncomfortably full; eating large amounts of food when not 
hungry; eating alone because of feelings of embarrassment about the quantity of food being eaten; or feeling disgusted, depressed, or guilty after binge eating. People with BED often experience physical health and mental health problems, and may also experience teasing and bullying because of their weight.

(4) Other specified feeding and eating disorder (OSFED) is a diagnosis that captures the fact that many people with eating problems do not fit into the categories of AN, BN, or BED. OSFED is the most common, and diverse, eating disorder diagnosis. For example, someone who has an OSFED may meet all criteria for AN, except their BMI is between 17.5 and $19.0 \mathrm{~kg} / \mathrm{m}^{2}$. Similarly, someone with at least a healthy weight may engage in binge eating or compensatory behaviors, but not at the frequency necessary for a BN or BED diagnosis. Although a person diagnosed with an OSFED does not fully meet the criteria for AN, BN, or BED, it does not mean that their eating disorder is not real or that it is not serious. The distress, risk of suicide, and medical complications associated with OSFED are equal to, and sometimes higher than, AN, $B N$, and BED.

\section{MYTHS ABOUT EATING DISORDERS}

One of the most common and harmful myths about eating disorders is that they only happen to young, wealthy, heterosexual, white, non-transgender girls, and women [3]. This myth is so engrained in our society that a famous study showed that mental-health clinicians sometimes dismiss eating disorder symptoms reported by someone who is not white [4]. This myth is harmful because many people who have eating disorders go unidentified and never get treatment. Recent research using samples of people from around the world have busted this myth by showing that eating disorders affect individuals of all ages, genders, sexual orientations, races, ethnicities, and socioeconomic statuses [3].

Another harmful myth is that a person must be underweight to have an eating disorder. In reality, most people with eating disorders are not underweight and eating disorders happen to people of all body shapes and sizes [1,5]. A related myth is that if a person is not underweight, their eating disorder is not severe. Although being underweight is medically unsafe, people with eating disorders who are not underweight can have serious health issues that cannot be seen with the naked eye, such as electrolyte imbalances, digestive problems, and/or cardiac issues $[6,7]$. Thus, eating disorders can have lethal health consequences in people of all body sizes.

Yet another harmful myth about eating disorders is that they are a choice. No one chooses to have an eating disorder. We know that eating disorders begin from complex interactions of biology with social, cultural, and environmental influences [3]. We do not have all 
1 https://www.aedweb. org/resources/onlinelibrary/publications/ nine-truths
FAMILY-BASED

TREATMENT (FBT)

A form of therapy in which family members take the lead in helping their child recover from an eating disorder. FBT is the treatment of choice for youth with eating disorders.

\section{COGNITIVE-}

BEHAVIORAL THERAPY (CBT)

A form of therapy that helps people recognize patterns and change thoughts, feelings, and behaviors that are causing problems in their lives. CBT is the treatment of choice for binge eating and bulimia nervosa. of the answers to why people develop eating disorders, but scientists are working hard to find these answers.

As you can see, there are lots of dangerous myths about eating disorders. If you want to learn more about eating disorder facts and misconceptions, we encourage you to have a look at the Academy for Eating Disorders Nine Truths about Eating Disorders ${ }^{1}$.

\section{WHAT ARE SOME WARNING SIGNS?}

You might be wondering how to know if you or a friend may be developing an eating disorder, so here are a few warning signs. One major warning sign is dieting or following strict rules about food and exercise, especially if you feel guilty or ashamed when you do not follow your diet, or your rules interfere with your social activities or schoolwork. It is also concerning if you find yourself constantly thinking about food and/or your body. Your friends may approach you about changes they have observed in your eating behaviors. Similarly, you might worry about a friend if they stop eating all the things they once loved. Another warning sign is a decline in performance in school, sports, or other activities. Last, feeling upset by your eating behaviors and/or body image concerns is another warning sign.

\section{HOW TO GET HELP}

A first step in seeking help is confiding in someone you trust, such as a teacher, counselor, coach, friend, sibling, parent, or other family member. If you are concerned about a friend, you can start by talking to your friend and asking if they would like help with approaching an adult for support. It is important to be aware that some friends may deny that they have a problem. In this case, it may be helpful to confide in an adult about your concerns for your friend.

Family-based treatment (FBT) is considered the best treatment for teens with $\mathrm{AN}$ and BN [8]. FBT involves the teen and their family (often parents and siblings) attending therapy sessions together with a therapist. The goal of FBT is for parents to help the teen build healthy eating habits and help the teen gain weight, in the case of AN. Siblings can act as supports for the teen. Individual therapy, such as cognitive-behavioral therapy (CBT; a treatment in which people evaluate the connections between their thoughts, emotions, and behaviors) is also used to treat BN and BED. For example, in CBT for $B N$ and BED, a main goal is to help the teen link emotions and thoughts to eating disorder behaviors. Researchers are continuing to develop and test new therapies to help increase the chance that people recover from their eating disorder. Being in therapy is hard work, but it is worth it to become healthy again. If you would like to learn even more about 
2 www.nationaleatingd isorders.org treatments for eating disorders, one helpful resource is the National Eating Disorders Association website ${ }^{2}$.

Now that you have read this article, you know more about what eating disorders are and know some common myths about these serious illnesses. The myths discussed in this paper are harmful because they often prevent people from getting the help that they need. Without proper treatment, people with eating disorders may experience poorer mental health and irreversible physical damages. As an eating disorder myth buster, you can play an important role in challenging incorrect information when you hear it and helping people know the facts about eating disorders.

\section{ACKNOWLEDGMENTS}

KC was funded by a TL1 postdoctoral fellowship awarded by the University of Kansas for Frontiers: University of Kansas Clinical and Translational Science Institute (\#TL1TR002368) through a CTSA grant from NCATS. KH was funded by a T32 postdoctoral fellowship awarded by Columbia University (T32MH096679). The contents of this manuscript are solely the responsibility of the authors and do not necessarily represent the official views of the University of Kansas, Columbia University, NIH, or NCATS.

\section{REFERENCES}

1. Lipson, S. K., and Sonneville, K. R. 2017. Eating disorder symptoms among undergraduate and graduate students at 12 U.S. colleges and universities. Eat. Behav. 24:81-8. doi: 10.1016/j.eatbeh.2016.12.003

2. American Psychiatric Association. 2013. Diagnostic and Statistical Manual of Mental Disorders (DSM-5). Arlington, VA: American Psychiatric Pub.

3. Schaumberg, K., Welch, E., Breithaupt, L., Hübel, C., Baker, J. H., Munn-Chernoff, M. A., et al. 2017. The science behind the academy for eating disorders' nine truths about eating disorders. Eur. Eat. Disord. Rev. 25:432-50. doi: 10.1002/er v. 2553

4. Gordon, K. H., Brattole, M. M., Wingate, L. R., and Joiner, T. E. 2006. The impact of client race on clinician detection of eating disorders. Behav. Ther. 37:319-25. doi: 10.1016/j.beth.2005.12.002

5. Flament, M. F., Henderson, K., Buchholz, A., Obeid, N., Nguyen, H. N. T., Birmingham, M., et al. 2015. Weight status and DSM-5 diagnoses of eating disorders in adolescents from the community. J. Am. Acad. Child Adolesc. Psychiatry. 54:403-11.e2. doi: 10.1016/j.jaac.2015.01.020

6. Wassenaar, E., Friedman, J., and Mehler, P. S. 2019. Medical complications of binge eating disorder. Psychiatr. Clin. North Am. 42:275-86. doi: 10.1016/j.psc. 2019.01.010

7. Westmoreland, P., Krantz, M. J., and Mehler, P. S. 2016. Medical complications of anorexia nervosa and bulimia. Am. J. Med. 129:30-7. doi: 10.1016/j.amjmed.20 15.06.031 
8. Lock, J., and le Grange, D. 2005. Family-based treatment of eating disorders. Int. J. Eat. Disord. 37:S64-7; discussion S87-9. doi: 10.1002/eat.20122

SUBMITTED: 23 March 2020; ACCEPTED: 14 September 2020; PUBLISHED ONLINE: 26 October 2020.

EDITED BY: Kelly Westlake, University of Maryland, Baltimore, United States

CITATION: Christensen KA and Hagan KE (2020) Taking a Bite Out of Eating Disorders: Facts and Myths. Front. Young Minds 8:545034. doi: 10.3389/frym.2020. 545034

CONFLICT OF INTEREST: The authors declare that the research was conducted in the absence of any commercial or financial relationships that could be construed as a potential conflict of interest.

COPYRIGHT (c) 2020 Christensen and Hagan. This is an open-access article distributed under the terms of the Creative Commons Attribution License (CC BY). The use, distribution or reproduction in other forums is permitted, provided the original author(s) and the copyright owner(s) are credited and that the original publication in this journal is cited, in accordance with accepted academic practice. No use, distribution or reproduction is permitted which does not comply with these terms.

\section{YOUNG REVIEWERS}

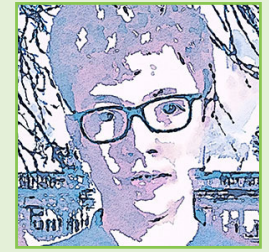

\section{JOHANNES, AGE: 13}

I am very interested in science and it is very interesting to review these papers from real scientists who know very much about their specialist field! Many of the papers explain very dangerous illnesses for the human population to children and I think this information is important to know!

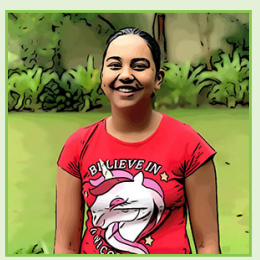

\section{NIKITA, AGE: 12}

$\mathrm{Hi}$, I am Nikita. I love creating and appreciating all forms of art (literature, drawing, dance, and music). I am specifically interested in cosmology, mathematics, and biology.

\section{AUTHORS}

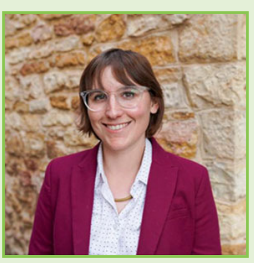

\section{KARA A. CHRISTENSEN}

Dr. Christensen is a post-doctoral fellow at the University of Kansas in the Department of Psychology. Her research focuses on understanding how relationships, such as friendships, can improve mental health or make people's lives more challenging. In particular, she is interested in how relationships impact symptoms of eating disorders in young adults. She hopes to use her research to guide therapists in helpful ways to involve friends and family members in the recovery process. *christensen@ku.edu 


\section{KELSEY E. HAGAN}

Kelsey Hagan, Ph.D., is a post-doctoral research fellow within the Department of Psychiatry at Columbia University Medical Center. Dr. Hagan's research focuses on understanding how brain activity and brain structure differs between people with and without eating disorders. In particular, Dr. Hagan is interested in how persons with eating disorders make decisions, particularly when experiencing emotion and stress. Dr. Hagan is also interested in establishing scientifically based definitions of eating disorders and binge eating. Dr. Hagan hopes that her research will improve treatments for persons with eating disorders. 